University of Nebraska - Lincoln

DigitalCommons@University of Nebraska - Lincoln

$9-2009$

\title{
ATP Release by Infected Bovine Monocytes Increases the Intracellular Survival of Mycobacterium avium Subsp. paratuberculosis
}

Seng-Ryong Woo

University of Wisconsin-Madison, Madison, WI

Raul G. Barletta

University of Nebraska - Lincoln, rbarletta1@unl.edu

Charles Czuprynski

University of Wisconsin-Madison, Madison, WI 53706, USA

Follow this and additional works at: https://digitalcommons.unl.edu/vetscipapers

Part of the Veterinary Medicine Commons

Woo, Seng-Ryong; Barletta, Raul G.; and Czuprynski, Charles, "ATP Release by Infected Bovine Monocytes Increases the Intracellular Survival of Mycobacterium avium Subsp. paratuberculosis" (2009). Papers in Veterinary and Biomedical Science. 105.

https://digitalcommons.unl.edu/vetscipapers/105

This Article is brought to you for free and open access by the Veterinary and Biomedical Sciences, Department of at DigitalCommons@University of Nebraska - Lincoln. It has been accepted for inclusion in Papers in Veterinary and Biomedical Science by an authorized administrator of DigitalCommons@University of Nebraska - Lincoln. 
Published in Comparative Immunology, Microbiology and Infectious Diseases 32:5 (September 2009), pp. 365-377; doi 10.1016/j.cimid.2007.11.003 Copyright ( 2008 Elsevier Ltd Used by permission. http://www.sciencedirect.com/science/journal/01479571

Accepted November 1, 2007; published online February 19, 2008.

\title{
ATP release by infected bovine monocytes increases the intracellular survival of Mycobacterium avium subsp. paratuberculosis
}

\author{
Seng-Ryong Woo, ${ }^{1}$ Raúl G. Barletta, ${ }^{2}$ and Charles J. Czuprynski ${ }^{1}$
}

\author{
${ }^{1}$ Department of Pathobiological Sciences, School of Veterinary Medicine, \\ University of Wisconsin-Madison, Madison, WI 53706, USA \\ ${ }^{2}$ Department of Veterinary and Biomedical Sciences, University of Nebraska-Lincoln, \\ Lincoln, NE 68583-0905, USA \\ Corresponding author - C. J. Czuprynski, Department of Pathobiological Sciences, School of Veteri- \\ nary Medicine, University of Wisconsin-Madison, 2015 Linden Drive, Madison, WI 53706, USA; \\ tel 608 262-8102, fax 608 262-8102, email czuprync@svm.vetmed.wisc.edu
}

\begin{abstract}
Mycobacterium avium subsp. paratuberculosis is the etiologic agent of Johne's disease, a chronic intestinal infection in ruminants. Adenosine $5^{\prime}$-Triphosphate (ATP) has been reported to induce killing of several Mycobacterium species in human and murine macrophages. We investigated whether ATP secreted from M. avium subsp. paratuberculosis-infected bovine monocytes affects intracellular survival of the bacilli. Bovine monocytes constitutively secreted ATP during an 8-day incubation period in vitro; however, M. avium subsp. paratuberculosis infection did not enhance ATP release. Removal of extracellular ATP by the addition of apyrase increased the viability of infected monocytes, but surprisingly decreased the number of viable intracellular bacilli. In contrast to previous reports, addition of extracellular ATP $(1 \mathrm{mM})$ increased intracellular survival of M. avium subsp. paratuberculosis in bovine monocytes. Neither apyrase nor ATP altered production of reactive oxygen intermediates (ROI) or reactive nitrogen intermediates (RNI) by bovine monocytes. These results suggest that ATP release from infected bovine monocytes improves, rather than decreases, the intracellular survival of M. avium subsp. paratuberculosis.
\end{abstract}

Keywords: Mycobacterium subsp. paratuberculosis, bovine, monocytes, ATP, purinergic 


\begin{abstract}
Résumé
Mycobacterium avium sous-espèce paratuberculosis est l'agent étiologique de la maladie de Johne, une infection intestinale chronique des ruminants. L'adénosine 5'-Triphosphate (ATP) est connue pour induire la mort de plusieurs espèces de mycobactéries dans les macrophages humains et murins. Nous avons recherché si l'ATP secrétée par Mycobacterium avium paratuberculosis infectant les monocytes bovins affecte la survie intracellulaire des bacilles. Les monocytes bovins ont secrété de l'ATP pendant huit jours in vitro. Cependant, l'infection par Mycobacterium avium paratuberculosis n'augmente pas le taux d'ATP. Le déplacement de l'ATP extracellulaire par l'addition d'apyrase a augmenté la viabilité des monocytes infectés mais, étonnamment a diminué le nombre de bacilles intracellulaires viables. Contrairement au rapport précédent, l'addition d'ATP extracellulaire $(1 \mathrm{mM})$ a augmenté la survie intracellulaire de Mycobacterium paratuberculosis avium dans les monocytes de bovins. $\mathrm{Ni}$ l'apyrase ni l'ATP n'ont modifié la production des réactions oxygènes intermédiaires (ROI) ou des réactions intermédiaires d'azote (RNI) dans les monocytes de bovins. Ces résultats suggèrent que le dégagement d'ATP à partir des monocytes de bovins infectés augmente plutôt que diminue la survie intracellulaire de Mycobacterium avium paratuberculosis.
\end{abstract}

Mots clés: paratuberculose, maladie de Johne, Mycobacterium avium paratuberculosis, ATP

\title{
1. Introduction
}

Mycobacterium avium subsp. paratuberculosis is the etiologic agent of paratuberculosis (Johne's disease), a chronic granulomatous enteritis of ruminants [1]. There is reason to believe that some infected cows control M. avium subsp. paratuberculosis infection and do not develop clinical disease [2]. We know relatively little about the innate immune mechanisms that control the survival of M. avium subsp. paratuberculosis in bovine mononuclear phagocytes.

Adenosine 5'-Triphosphate (ATP) is secreted by lytic and nonlytic mechanisms from many types of cells, including monocytes and macrophages [3]. Once released, ATP binds to purinergic receptors (P2X) on the cell surface and modulates various cellular functions [4]. There have been several reports that addition of ATP induces apoptosis of macrophages and kills intracellular Mycobacterium species in human and murine macrophages [5-10]. For example, ATP binding to $\mathrm{P} \mathrm{X}_{7}$ receptors increased intracellular calcium and phospholipase D (PLD) activity, and subsequently increased phagosome-lysosome fusion in Mycobacterium tuberculosis-infected human macrophages [8]. There is one report that ATP binding to $\mathrm{P} 2 \mathrm{X}_{7}$ receptors on bovine macrophages stimulated intracellular killing of M. bovis BCG [11].

Some cell types constitutively secrete ATP in culture at $\mathrm{pM}$ to $\mathrm{nM}$ concentrations [3]. ATP secreted from murine macrophages-induced spontaneous cell death; addition of apyrase, an ectoenzyme that hydrolyses ATP, enhanced macrophage viability [12]. As described above, addition of ATP (3-5 mM)-induced killing of intracellular Mycobacterium tuberculosis and Mycobacterium bovis BCG in human and murine macrophages, respectively [5-10]. However, there have been 
no published reports on whether endogenously secreted ATP affects the intracellular survival of Mycobacterium species in mononuclear phagocytes.

In this study, we hypothesized that ATP secreted from M. avium subsp. paratuberculosis-infected monocytes would be cytotoxic to bovine monocytes and kill the intracellular bacilli. As expected, we observed that removal of extracellular ATP by addition of apyrase increased the viability of infected monocytes. However, to our surprise apyrase also decreased the intracellular survival of M. avium subsp. paratuberculosis. Conversely, short-term addition of ATP to the culture medium increased the number of viable $M$. avium subsp. paratuberculosis in infected monocytes. These data suggest that ATP release from infected bovine monocytes enhances, rather than diminishes, the intracellular survival of $M$. avium subsp. paratuberculosis.

\section{Materials and methods}

\subsection{Bacteria culture}

M. avium subsp. paratuberculosis strain K-10 was grown to a final concentration of $10^{8} \mathrm{CFU} / \mathrm{ml}$ in Middlebrook 7H9 broth (Difco laboratories, Detroit, MI) supplemented with 10\% oleic acid-albumin-dextrose-catalase (OADC; Becton Dickinson Microbiology System, Sparks, MD), 0.05\% Tween 80 and $2 \mu \mathrm{g} / \mathrm{ml}$ of mycobactin J (Allied Laboratories, Ames, Iowa). After harvesting and washing the bacteria with phosphate-buffered saline, single-cell suspensions of bacteria were made by using a motor-driven overhead stirrer and glass-Teflon homogenizer in a biosafety cabinet. To further remove clumped bacteria, the bacterial cells were allowed to settle for $30 \mathrm{~min}$ and the supernatant was centrifuged for $10 \mathrm{~min}$ at $200 \times g$. The bacteria in the supernatant were resuspended in PBS plus $10 \%$ glycerol, aliquoted and stored at $-70^{\circ} \mathrm{C}$. The number of viable bacteria in the stock was determined by a radiometric (BACTEC) method, or by plate counts on $7 \mathrm{H} 10$ agar (CFU). For microscopic counting and differentiation of viable bacterial cells, the Live/Dead Baclight bacterial viability kit (Molecular Probes Inc., Eugene, Oregon) was used with the aid of a Petroff-Hauser chamber. Before each assay, an aliquot was thawed, diluted in RPMI-1640 medium without antibiotics and used for infection of cells in vitro.

\subsection{Bovine monocytes}

For isolation of bovine monocytes, blood was collected from the tail vein of healthy donor cows in the UW-Madison Dairy Science herd, using sodium citrate $(0.38 \%(\mathrm{v} / \mathrm{v})$ final concentration) as anticoagulant. Although this herd does not have a history of clinical Johne's disease, one cow tested positive (by ELISA) for Johne's each of the past 2 years and was culled. Neither of these cows were used as a blood donor in this study. The blood was centrifuged for $30 \mathrm{~min}$ at $400 \times g$ and the plasma was removed. The buffy coat cells were resuspended in $35 \mathrm{ml}$ of Hanks balanced salts solution (HBSS; Mediatech Inc., Herndon, VA) containing 4 mM EDTA, layered over $15 \mathrm{ml}$ of Ficoll-Histopaque 1083 (Sigma Diagnostic Inc., St. Louis, MO) and centrifuged at room temperature for $40 \mathrm{~min}$ at $600 \times \mathrm{g}$. The mononuclear cells were collected from the interface, the red blood cells were 
lysed with $\mathrm{RBC}$ lysis buffer (150 $\mathrm{mM} \mathrm{NH}_{4} \mathrm{Cl}$ and $10 \mathrm{mM}$ Tris, $\left.\mathrm{pH} 7.5\right)$ and washed three times with HBSS. The isolated mononuclear cells were resuspended in RPMI-1640 medium (Mediatech Inc., Herndon, VA) supplemented with 1\% FBS and adjusted to a concentration of $3 \times 10^{6}$ cells $/ \mathrm{ml}$. The cells were distributed $(1 \mathrm{ml}$ per well) into wells in a 24 -well tissue culture plate (FALCON BD labware, Franklin Lakes, NJ). The monocytes were allowed to adhere for $2 \mathrm{~h}$ at $37^{\circ} \mathrm{C}$ in $5 \%$ $\mathrm{CO}_{2}$ and nonadherent cells were removed by washing with warm RPMI 1640. Adherent monocytes were used for infection assays and cultured in RPMI-1640 with 10\% FBS (ATLANTA Biologicals, Lawrenceville, GA) without antibiotics. At the time of infection, the estimated number of adherent cells was approximately $2 \times 10^{5} /$ well.

\subsection{Measurement of ATP release from bovine monocytes}

Monocytes were infected with $M$. avium subsp. paratuberculosis at a multiplicity of infection (MOI) of 10:1 (bacteria:monocyte) in the presence of 10\% autologous serum for $3 \mathrm{~h}$ at $37^{\circ} \mathrm{C}$ in $5 \% \mathrm{CO}_{2}$. The uningested bacilli were removed by washing three times with warm RPMI, and the monocytes were incubated further in RPMI with 10\% FBS without antibiotics. Half of the medium was replaced with fresh RPMI supplemented with 10\% FBS without antibiotics at day 4 . At the indicated time points, we collected conditioned media, which were centrifuged at $200 \times g$ for $5 \mathrm{~min}$ at $4{ }^{\circ} \mathrm{C}$. The supernatants were distributed into wells $(100 \mu \mathrm{l}$ each well) of an opaque 96-well plate and an equal volume of CellTiter-Glo Luminescent Cell Viability reagent (Promega, Madison, WI) was added to the wells and incubated for $10 \mathrm{~min}$ at room temperature. The luminescent signal was measured using a luminometer (The Reporter; Turner Biosystems, Sunnyvale, CA). A series of dilutions of a known concentration of ATP was used to generate a standard curve from which ATP concentrations in the samples were estimated by extrapolation. In some experiments, we added $5 \mathrm{U}$ of apyrase (grade VI, Sigma, St. Louis, MO) into the wells of M. avium subsp. paratuberculosis-infected monocytes at day 0 and day 4 after infection, and the ATP concentration in the conditioned media was measured as described above.

\subsection{Quantitation of viable intracellular M. avium subsp. paratuberculosis}

Infected monocytes were cultured in RPMI media supplemented with $10 \%$ FBS without antibiotics for up to 8 days at $37^{\circ} \mathrm{C}$ in $5 \% \mathrm{CO}_{2}$. In some experiments, $5 \mathrm{U}$ or $10 \mathrm{U}$ of apyrase were added to the infected monocytes at the indicated time points. In other experiments, $0.1 \mathrm{mM}$ or $1 \mathrm{mM}$ Adenosine 5'-Triphosphate (ATP, Calbiochem, La Jolla, CA) was added to infected monocytes immediately, and 2 and 4 days after infection. In all experiments, we harvested conditioned media from infected monocytes at days 4 and 8 . The conditioned media were centrifuged at $2000 \times \mathrm{g}$ for $30 \mathrm{~min}$ and lysed with $0.05 \%$ SDS to release any bacilli within the detached cells. The adherent monocytes were similarly lysed with $0.05 \%$ SDS and the lysate inoculated into BACTEC 12B vials along with the conditioned media lysate from the same well. The numbers of viable bacilli were estimated by a radiometric method as described previously [13]. 


\subsection{Viability of infected monocytes}

The viability of infected monocytes was assessed using the CellTiter-Blue Cell Viability Assay (Promega, Madison, WI). Monocytes were infected with M. avium subsp. paratuberculosis as described above. The media was removed, replaced with $360 \mu \mathrm{l}$ of RPMI media supplemented with $10 \%$ FBS, and $40 \mu 1$ of CellTiter-Blue reagent was added to each well. The plate was incubated at $37^{\circ} \mathrm{C}$ for $2 \mathrm{~h}$ and the fluorescent intensity of each well was measured using a microplate reader (Synergy HT, Bio-Tek, Winooski, VT). The viability of apyrase treated monocytes was expressed as a percentage of the signal for untreated $M$. avium subsp. paratuberculosis-infected monocytes. We also differentiated live vs. dead monocytes using the LIVE/DEAD Viability/Cytotoxicity Kit (Product L3224, Invitrogen, Carlsbad, CA). The basis for this assay is that nonfluorescent Calcein AM is cleaved, by cytoplasmic esterases in intact cells, to calcein which gives an intense green fluorescence. In cells with a damaged cell membrane, ethidium homodimer-1 enters and binds to nucleic acids, resulting in an intense red stain. Infected monocytes were cultured in the presence or absence of apyrase, and Calcein AM $(1 \mu \mathrm{M}$ as final concentration) and Ethidium homodimer-1 ( $2 \mu \mathrm{M}$ as final concentration) were added to infected monocytes at the indicated time points. After incubation at $37^{\circ} \mathrm{C}$ for $10 \mathrm{~min}$, the stained cells were examined using an inverted fluorescence microscope (Olympus IX70, Leeds Precision Instrument, Minneapolis, MN) with appropriate filter sets (excitiaion wavelength $488 \mathrm{~nm}$, emission wavelength of $530 \mathrm{~nm}$ and $585 \mathrm{~nm}$ for calcein (green) and ethidium (red), respectively. Five different 400× magnification fields per well were examined and the numbers of live cells (green color) and dead cells (red color) were enumerated.

\subsection{Reactive oxygen intermediate (ROI) and nitrogen intermediate (RNI) production by monocytes}

ROI production by bovine monocytes was measured using Luminol (Calbiochem, La Jolla, CA). Bovine monocytes $\left(10^{5}\right.$ cells/well) were cultured in wells of a white opaque 96-well plate (Nunc, Denmark) to which Luminol (20 $\mu \mathrm{M})$ was added. After a $10 \mathrm{~min}$ incubation at $37^{\circ} \mathrm{C}$, M. avium subsp. paratuberculosis at MOI 10:1 (bacteria:monocyte), apyrase $(5 \mathrm{U})$ and ATP $(1 \mathrm{mM})$ were added to the wells. Unstimulated cells were used as a negative control, and cells incubated with $500 \mathrm{nM}$ phorbol 12-myristate 13-acetate (PMA) (FisherBiotech, Fair Lawn, NJ) was used as a positive control. The plate was then incubated at $37^{\circ} \mathrm{C}$ and photoemission was measured every $20 \mathrm{~min}$ for $120 \mathrm{~min}$ using a luminometer (The Reporter; Turner Biosystems, Sunnyvale, CA). To measure release of nitric oxide, conditioned media were collected, centrifuged at $200 \times g$ for $5 \mathrm{~min}$ and $50 \mu \mathrm{l}$ of each supernatant placed in separate wells of a 96-well plate. An equal amount of Griess reaction solution ( $0.1 \%$ naphthylethylenediamine dihydrochloride and 1\% sulfanilamide in $2.5 \%$ phosphoric acid) was added and the plate was incubated for $10 \mathrm{~min}$ at room temperature. The absorbance at $550 \mathrm{~nm}$ was measured with a plate reader ( $\mu$ Quant; Biotek instruments, Winooski, VT). A sodium nitrite solution was used to prepare a standard curve and the amount of $\mathrm{NO}_{2}{ }^{-}$was calculated by extrapolation. 

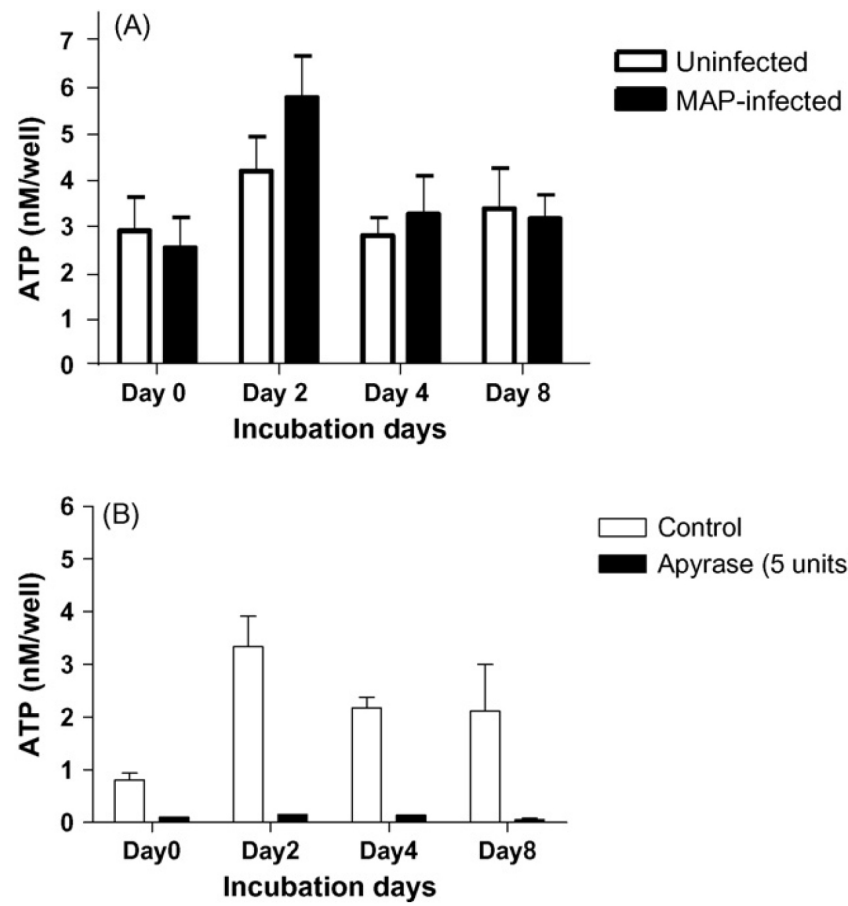

Figure 1. ATP release from uninfected or infected bovine monocytes. In (A), bovine monocytes were infected with M. avium subsp. paratuberculosis (MAP), as described in Section 2, and then incubated for up to 8 days at $37^{\circ} \mathrm{C}$ in RPMI 1640 medium supplemented with $10 \%$ FBS. Conditioned media from uninfected and infected monocytes were collected at the indicated time points, centrifuged at $200 \times g$ for 5 min at $4{ }^{\circ} \mathrm{C}$, and the supernatants analyzed for ATP using a luminescence assay (Promega, Madison, WI) as described in Section 2. In (B), 5 U of apyrase (grade VI) was added to infected monocytes at day 0 and day 4 after infection and ATP release measured by the same procedure described above. Data presented are the mean \pm S.E.M. of two independent experiments.

\section{Statistical analysis}

Data are presented as the mean \pm the S.E.M. and were analyzed by ANOVA followed by a Tukey post-test for significance using the Prism 3 Statistical Software package (GraphPad, San Diego, CA).

\section{Results}

\subsection{ATP release from bovine monocytes}

Bovine monocytes constitutively released $\mathrm{nM}$ concentrations of ATP into the conditioned media during an 8-day incubation period. Prior ingestion of M. avium subsp. paratuberculosis did not significantly increase the amounts of ATP detected in monocyte conditioned medium (Figure 1A). Addition of apyrase, an ATP hydrolysis enzyme, completely removed ATP from conditioned media (Figure 1B). 

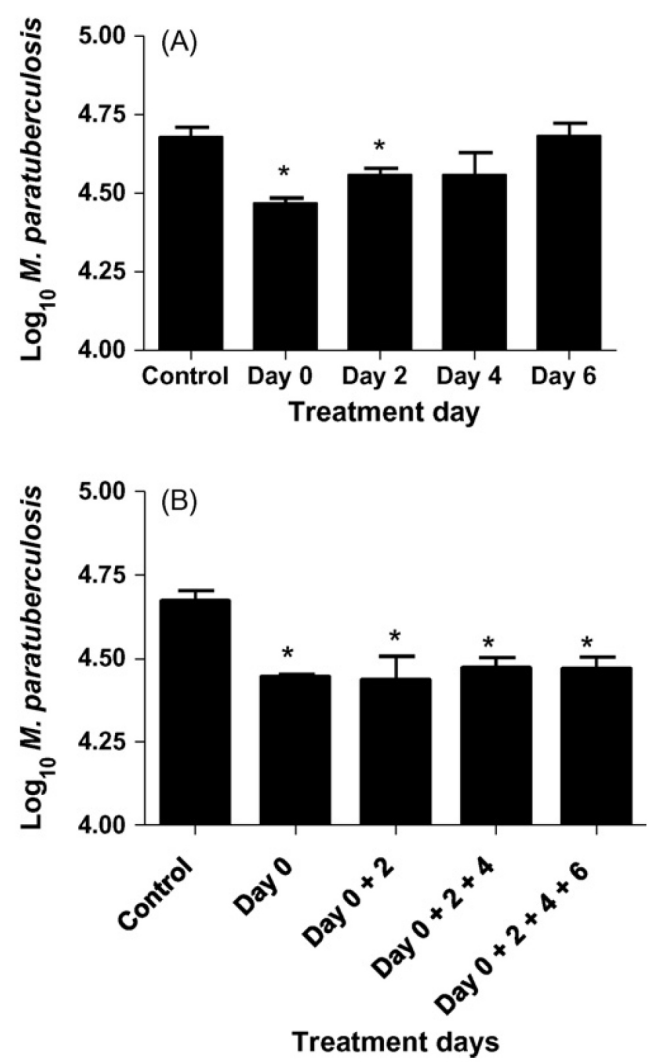

Figure 2. Intracellular survival of $M$. avium subsp. paratuberculosis in bovine monocytes after a single (A) or multiple (B) treatments with apyrase. Bovine monocytes were incubated with M. paratuberculosis at a multiplicity of infection (MOI) of 10:1 (bacilli:monocyte) as described in Section 2. At the indicated time points, $5 \mathrm{U}$ of apyrase was added and the infected cells further incubated until 8 days. At that point the cells were lysed, and the lysates and conditioned media from individual wells combined and inoculated into BACTEC 12B vials. The growth index was recorded every $24 \mathrm{~h}$ and the number of viable bacilli was calculated as described in Section 2. The data are the mean \pm S.E.M. of two independent experiments $\left({ }^{*} P<0.05\right)$.

4.2. Addition of apyrase decreases intracellular survival of M. avium subsp. paratuberculosis in bovine monocytes

To examine the effect of ATP release on intracellular survival of M. avium subsp. paratuberculosis, we treated infected monocytes with apyrase (an ATP diphosphohydrolase) at several time points. A single addition of apyrase reduced the number of viable $M$. paratuberculosis at 8 days after infection. The effect of apyrase was greater when added at day 0 , rather than day 2 or day 4 , and disappeared when addition of apyrase was delayed until 6 days after infection (Figure 2A). There was no greater reduction in CFU of M. avium subsp. paratuberculosis when apyrase was added more than once, as compared to a single treatment at day 0 (Figure 2B). When apyrase was added to infected monocytes at day 0 and day 4 after infection, we observed decreased numbers of viable intracellular $M$. 


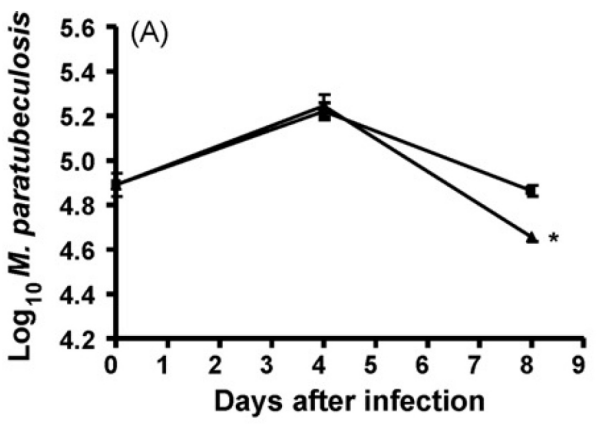

$\rightarrow$ Control
$\rightarrow$ Apyrase (5 units)
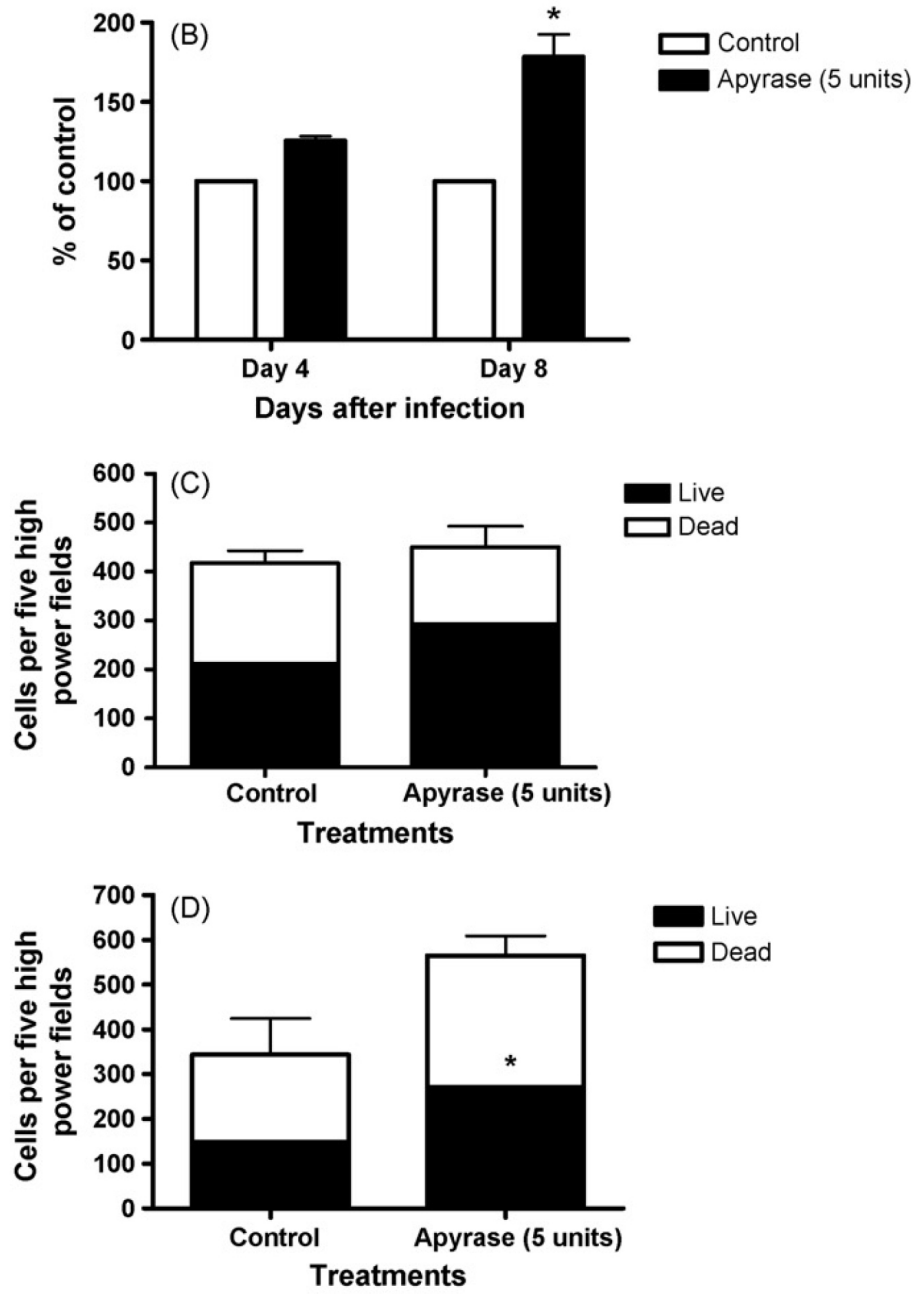

Figure 3. Effect of apyrase treatment on intracellular survival of $M$. avium subsp. paratuberculosis and viability of infected monocytes. In (A), bovine monocytes were infected with M. avium subsp. paratuberculosis as described in Section 2. Apyrase (5 U) was added to infected monocytes immediately after and 4 days after infection. At the indicated time points, monocytes were lysed and the lysates combined with the conditioned media from the same wells and inoculated into BACTEC 12B vials. The growth index was recorded every $24 \mathrm{~h}$ and the number of viable bacilli was calculated as described in Section 2. In (B), 


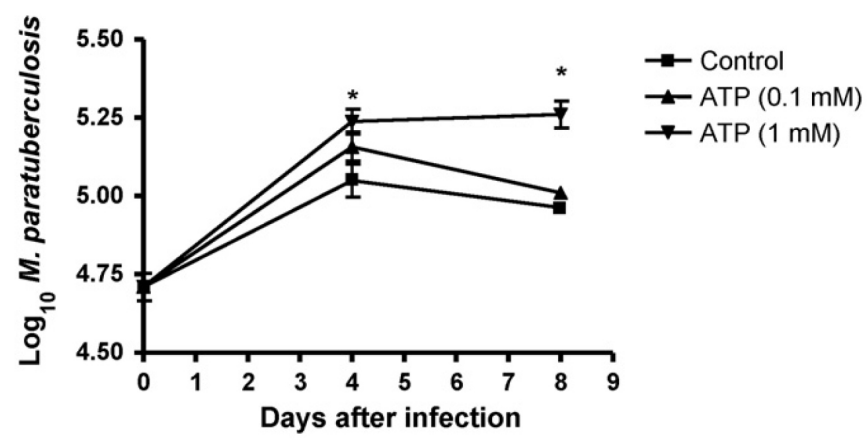

Figure 4. Intracellular survival of M. avium subsp. paratuberculosis is increased by addition of ATP. Bovine monocytes were infected with M. avium subsp. paratuberculosis as described earlier and ATP $(0.1 \mathrm{mM}$ or $1 \mathrm{mM})$ was added at 0,2 and 4 days after infection. At the indicated time points, monocytes were lysed, and the lysates and conditioned media from the same wells combined and inoculated into BACTEC 12B vials. The growth index was recorded every $24 \mathrm{~h}$ and the number of viable bacilli calculated as described in Section 2 . The results are the mean \pm S.E.M. for two independent experiments $\left({ }^{*} P<0.05\right)$.

avium subsp. paratuberculosis at day 8 (Figure 3A), but there was no significant effect of apyrase on intracellular bacilli at day 4 .

Adding apyrase significantly increased monocyte viability by approximately $80 \%$ at day 8 , as measured by an AlamarBlue assay (Figure 3B). We also performed Live/Dead staining (Invitrogen Product L3224) of monocytes at the same time points, and counted numbers of live and dead cells using inverted fluorescent microscopy. These data confirmed there were greater numbers of viable monocytes, and fewer viable bacilli, following apyrase treatment at 4 and 8 days after infection (Figure 3C and D). Taken as a whole, these data suggest that ATP released from infected monocytes supports survival of M. avium subsp. paratuberculosis, but reduces the viability of infected monocytes.

\subsection{Adding exogenous ATP increases intracellular survival of M. avium subsp. paratu- berculosis in bovine monocytes}

We next added $0.1 \mathrm{mM}$ or $1 \mathrm{mM}$ ATP to M. avium subsp. paratuberculosis-infected monocytes at day 0, day 2 and day 4 after infection, and measured the number of viable bacilli by a radiometric method. Consistent with our apyrase data, adding $1 \mathrm{mM}$ ATP significantly increased intracellular survival of $M$. avium

infected monocytes were treated with $5 \mathrm{U}$ of apyrase immediately after and 4 days after infection). At the indicated time points, the conditioned media were removed, and monocyte viability assessed by staining with resazurin (Promega, Madison, WI) as described in Section 2. After a $2 \mathrm{~h}$ incubation, the fluorescent intensity of each well was measured with a fluorescent plate reader and the viability of apyrase treated monocytes expressed as the percentage increase compared to untreated monocytes. As a second measure of monocyte viability, apyrase-treated and untreated M. avium subsp. paratuberculosis-infected monocytes at 4 days (C) and 8 days (D) of infection were stained with the Live/Dead kit (Invitrogen) as described in Section 2. The monocytes were examined with an inverted fluorescent microscope and the numbers of live (green) and dead (red) monocytes in five different $400 \times$ fields were counted. Results are presented as the mean \pm S.E.M. of three independent experiments $\left({ }^{*} P<0.05\right)$. 

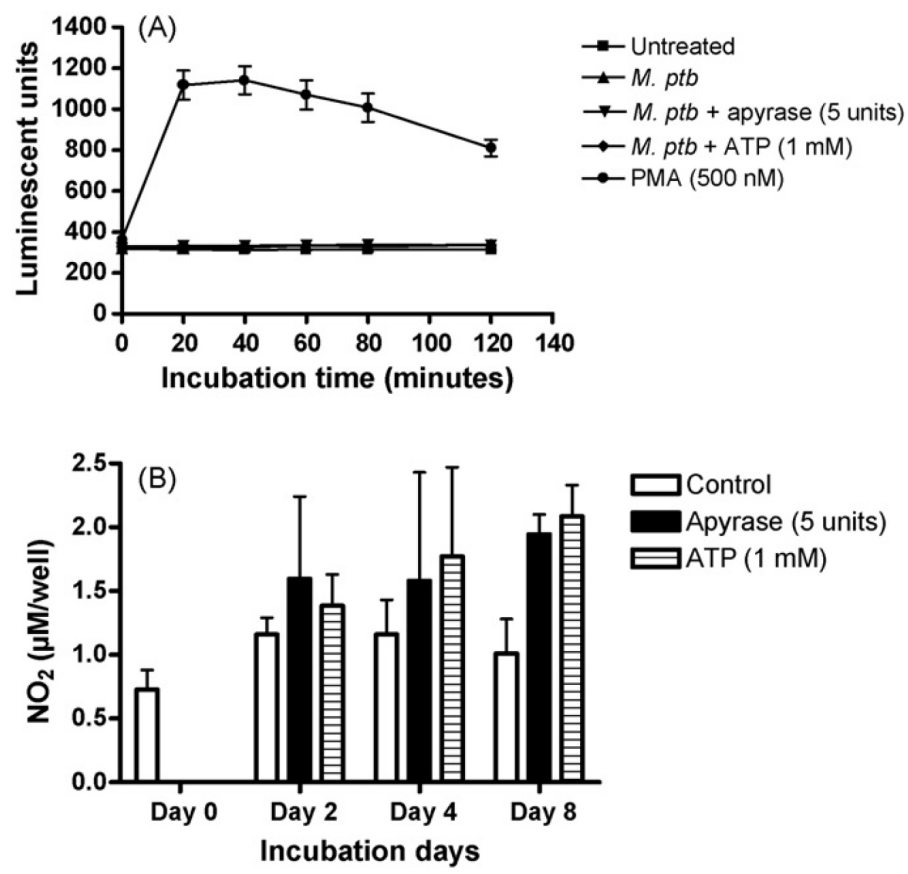

Figure 5. Addition of apyrase $(5 \mathrm{U})$ or ATP $(1 \mathrm{mM})$ does not alter production of ROI (A) or RNI (B) by bovine monocytes. To measure ROI (A) bovine monocytes were cultured in a white opaque 96-well plate (Nunc, Denmark) and Luminol $(20 \mu \mathrm{M})$ and stimuli were added in RPMI media (Mediatech Inc., Herndon, VA). The cells were incubated for $120 \mathrm{~min}$ and photoemission was measured every $20 \mathrm{~min}$ with a Luminometer. Monocytes incubated with PMA $(500 \mathrm{nM})$ were used as a positive control. To measure nitric oxide production $(\mathrm{B})$, apyrase $(5 \mathrm{U})$ was added to infected monocytes immediately after and 4 days after infection, or ATP $(1 \mathrm{mM})$ was added at 0,2 and 4 days after infection. The conditioned media were collected from each sample, centrifuged and RNI production measured with the Griess reagent as described in Section 2. The results are the mean \pm S.E.M. of two independent experiments.

subsp. paratuberculosis (Figure 4). We also observed decreased viability of infected monocytes at the same time points (data not shown).

4.4. Addition of apyrase or ATP does not alter production of ROI and RNI by M. avium subsp. paratuberculosis-infected bovine monocytes

To investigate possible mycobactericidal mechanisms, we measured ROI and RNI production from $M$. avium subsp. paratuberculosis-infected monocytes after addition of apyrase or ATP. M. avium subsp. paratuberculosis infection did not stimulate production of ROI by bovine monocytes. Nor did addition of apyrase $(5 \mathrm{U})$ or ATP $(1 \mathrm{mM})$ alter production of ROI by bovine monocytes (Figure $5 \mathrm{~A})$. Likewise, bovine monocytes infected with $M$. avium subsp. paratuberculosis produced low levels $(\mu \mathrm{M})$ of nitric oxide that were not significantly altered by addition of apyrase or ATP (Figure 5B). 


\section{Discussion}

M. avium subsp. paratuberculosis infection in the intestinal tract of cattle results in granulomatous lesions that contain mononuclear phagocytes with intracellular bacilli [12]. Some of these infected cells may undergo apoptosis or necrosis, and could serve as a source of extracellular ATP. It is also reported that many different types of cells, including mononuclear phagocytes, secrete ATP by a nonlytic mechanism [3]. Once released, ATP can bind to purinergic receptors on the surface of nearby cells and evoke a variety of cellular responses [4].

Bovine monocytes constitutively secreted ATP (1-6 nM) during an 8-day incubation period. However, M. avium subsp. paratuberculosis infection did not enhance ATP secretion. These observations are similar to a previous report that murine macrophages constitutively release $\mathrm{nM}$ concentrations of ATP, that was not enhanced by addition of bacterial endotoxin (LPS) [14]. However, other investigators reported that LPS enhanced release of ATP from bovine endothelial cells [15]. It has been reported that thrombin, bradykinin, ADP, and oxidative stress increase ATP release from various cells [16] and [17]. Chlamydia pneumoniae was reported to increase intracellular ATP in murine macrophages by a Toll-like receptor 2-dependent manner, but these authors did not describe release of extracellular ATP in the same experiments [18]. We observed that M. avium subsp. paratuberculosis increased intracellular ATP in bovine monocytes (data not shown), but saw no significant change in extracellular ATP secreted from infected monocytes.

Addition of apyrase, which hydrolyzes ATP, completely removed extracellular ATP from the conditioned media. A single apyrase treatment decreased survival of $M$. avium subsp. paratuberculosis at 8 days after infection. The effect of apyrase was not enhanced by multiple treatments. Previously, other researchers reported that addition of extracellular ATP (3-5 mM)-induced killing of intracellular Mycobacterium species in human and murine macrophages [5-10]. In contrast to our observation, those earlier reports suggest that ATP suppressed intracellular survival of Mycobacterium species in human and murine macrophages. However, these experiments differed from our own in that we used apyrase to remove nM levels of endogenously secreted ATP, whereas the previous reports examined mycobacterial killing when exogenous ATP (3-5 mM) was added to the media [6]. To confirm that endogenous ATP supports the intracellular survival of $M$. avium subsp. paratuberculosis in bovine monocytes, we added relatively low concentrations of ATP $(0.1 \mathrm{mM}$ or $1 \mathrm{mM})$ to infected monocytes. Addition of extracellular ATP increased the survival of M. avium subsp. paratuberculosis, but decreased the viability of infected monocytes at day 4 and day 8 after ATP treatment (data not shown). These observations are similar to other data we have reported in which short term $(24 \mathrm{~h})$ incubation with higher concentrations $(5 \mathrm{mM})$ of ATP or benzyl-ATP was cytotoxic to bovine monocytes, but did not reduce the viability of M. avium subsp. paratuberculosis [19]. Nor did we observe in that study an effect of a $24 \mathrm{~h}$ incubation with $5 \mathrm{mM}$ ATP on the numbers of viable Mycobacterium bovis $\mathrm{BCG}$ recovered from bovine monocytes.

Our data suggest that endogenous ATP is cytotoxic to bovine monocytes and slightly increased intracellular survival of M. avium subsp. paratuberculosis. Our observations are similar to a previous report that the J774 murine macrophage cell line spontaneously died during a 6-day incubation, and this cell death was 
dependent on expression of the $\mathrm{P} 2 \mathrm{z}$ receptor [12]. The same report also showed that apyrase rescued J774 cells from cell death [12]. Similarly, a separate report showed that apyrase decreased apoptosis of bovine endothelial cells in response to constitutive release of ATP [15].

How does removal of endogenous ATP enhance the killing of intracellular $M$. avium subsp. paratuberculosis in bovine monocytes? We considered the possibility that production of reactive oxygen or nitrogen was important. However, addition of neither apyrase nor ATP $(1 \mathrm{mM})$ altered production of ROI and RNI by M. avium subsp. paratuberculosis-infected bovine monocytes. Bovine monocytes in general have a poor ability to produce reactive oxygen and nitrogen intermediates [20-22]. Our observations are consistent with a previous report that apyrase did not affect LPS stimulated production of nitric oxide by murine macrophages [14]. We also considered the possible role of calcium influx and phospholipase $\mathrm{D}$ in our experimental system. In preliminary experiments we did not observe an increase in intracellular $\mathrm{Ca}^{2+}$ in ATP-treated monocytes; whereas an increase in intracellular $\mathrm{Ca}^{2+}$ was observed in ionomycin $(1 \mu \mathrm{M})$ treated monocytes, without any change in recovery of viable bacilli (data not shown). Nor did addition of ethanol $(1 \%, \mathrm{v} / \mathrm{v})$, which is reported to prevent phospholipase D activation and increase survival of Mycobacterium tuberculosis in the ATP-treated THP-1 human macrophage cell line [8], affect survival of M. avium subsp. paratuberculosis in bovine monocytes (data not shown).

In summary, we observed that removal of ATP from the culture medium of M. avium subsp. paratuberculosis-infected bovine monocytes increased monocyte viability and decreased intracellular survival of $M$. avium subsp. paratuberculosis. These data suggest that endogenous production of ATP might play a role in regulating the intracellular survival of $M$. avium subsp. paratuberculosis in bovine monocytes.

\section{Acknowledgments}

This work was supported by funds from the Wisconsin Agricultural Experimental Station (WIS 00770) and the U.S. Department of Agriculture National Research Institute (CSREESNRI 2004-35204-14231).

\section{References}

[1] O. Chacon, L. E. Bermudez, and R. G. Barletta, Johne's disease inflammatory bowel disease, and Mycobacterium paratuberculosis, Ann Rev Microbiol 58 (2004), pp. 329-363.

[2] M. Z. Tessema, A. P. Koets, V. P. Rutten, and E. Gruys, How does Mycobacterium avium subsp. paratuberculosis resist intracellular degradation?, Vet Q 23 (2001), pp. 153-162.

[3] E. R. Lazarowski, R. C. Boucher, and T. K. Harden, Mechanisms of release of nucleotides and integration of their action as P2X- and P2Y-receptor activating molecules, Mol Pharmacol 64 (2003), pp. 785-795.

[4] F. Di Virgilio, P. Chiozzi, D. Ferrari, S. Falzoni, J. M. Sanz, and A. Morelli et al. , Nucleotide receptors: an emerging family of regulatory molecules in blood cells, Blood 97 (2001), pp. 587-600.

[5] A. Molloy, P. Laochumroonvorapong, and G. Kaplan, Apoptosis, but not necrosis, of infected monocytes is coupled with killing of intracellular bacillus Calmette-Guerin, J Exp Med 180 (1994), pp. 1499-1509. 
[6] D. A. Lammas, C. Stober, C. J. Harvey, N. Kendrick, S. Panchalingam, and D. S. Kumararatne, ATP-induced killing of mycobacteria by human macrophages is mediated by purinergic P2Z(P2X7) receptors, Immunity 7 (1997), pp. 433-444.

[7] I. P. Fairbairn, C. B. Stober, D. S. Kumararatne, and D. A. Lammas, ATP-mediated killing of intracellular mycobacteria by macrophages is a $\mathrm{P} 2 \mathrm{X}(7)$-dependent process inducing bacterial death by phagosome-lysosome fusion, J Immunol 167 (2001), pp. 3300-3307.

[8] D. J. Kusner and J. A. Barton, ATP stimulates human macrophages to kill intracellular virulent Mycobacterium tuberculosis via calcium-dependent phagosome-lysosome fusion, J Immunol 167 (2001), pp. 3308-3315.

[9] C. B. Stober, D. A. Lammas, C. M. Li, D. S. Kumararatne, S. L. Lightman, and C. A. McArdle, ATP-mediated killing of Mycobacterium bovis bacille Calmette-Guerin within human macrophages is calcium dependent and associated with the acidification of mycobacteria-containing phagosomes, J Immunol 166 (2001), pp. 6276-6286.

[10] D. J. Kusner and J. Adams, ATP-induced killing of virulent Mycobacterium tuberculosis within human macrophages requires phospholipase D, J Immunol 164 (2000), pp. 379-388.

[11] R. A. Smith, A. J. Alvarez, and D. M. Estes, The P2X7 purinergic receptor on bovine macrophages mediates mycobacterial death, Vet Immunol Immunopathol 78 (2001), pp. 249-262.

[12] P. Chiozzi, M. Murgia, S. Falzoni, D. Ferrari, and F. Di Virgilio, Role of the purinergic P2Z receptor in spontaneous cell death in J774 macrophage cultures, Biochem Biophys Res Commun 218 (1996), pp. 176-181.

[13] S. R. Woo, J. Sotos, A. P. Hart, R. G. Barletta, and C. J. Czuprynski, Bovine monocytes and a macrophage cell line differ in their ability to phagocytose and support the intracellular survival of Mycobacterium avium subsp. paratuberculosis, Vet Immunol Immunopathol 110 (2006), pp. 109-120.

[14] R. D. Beigi and G. R. Dubyak, Endotoxin activation of macrophages does not induce ATP release and autocrine stimulation of P2 nucleotide receptors, J Immunol 165 (2000), pp. 7189-7198.

[15] M. J. Sylte, C. J. Kuckleburg, T. J. Inzana, P. J. Bertics, and C. J. Czuprynski, Stimulation of P2X receptors enhances lipooligosaccharide-mediated apoptosis of endothelial cells, J Leukoc Biol 77 (2005), pp. 958-965.

[16] S. Yang, D. J. Cheek, D. P. Westfall, and I. L. Buxton, Purinergic axis in cardiac blood vessels. Agonist-mediated release of ATP from cardiac endothelial cells, Circ Res 74 (1994), pp. 401-407.

[17] S. Ahmad, A. Ahmad, M. Ghosh, C. C. Leslie, and C. W. White, Extracellular ATP-mediated signaling for survival in hyperoxia-induced oxidative stress, J Biol Chem 279 (2004), pp. 16317-16325.

[18] K. Yaraei, L. A. Campbell, X. Zhu, W. C. Liles, C. C. Kuo, and M. E. Rosenfeld, Effect of Chlamydia pneumoniae on cellular ATP content in mouse macrophages: role of Toll-like receptor 2, Infect Immunol 73 (2005), pp. 4323-4326.

[19] S. R. Woo, R. G. Barletta, and C. J. Czuprynski, Addition of extracellular ATP is cytotoxic to mononuclear phagocytes but does not induce killing of intracellular Mycobacterium avium subsp. paratuberculosis, Clin Vaccine Immunol 14 (2007), pp. 1078-1083.

[20] D. J. Weiss, O. A. Evanson, A. Moritz, M. Q. Deng, and M. S. Abrahamsen, Differential responses of bovine macrophages to Mycobacterium avium subsp. paratuberculosis and Mycobacterium avium subsp. avium, Infect Immunol 70 (2002), pp. 5556-5561.

[21] B. Zhao, M. T. Collins and C. J. Czuprynski, Effects of gamma interferon and nitric oxide on the interaction of Mycobacterium avium subsp. paratuberculosis with bovine monocytes, Infect Immunol 65 (1997), pp. 1761-1766.

[22] B. G. Zurbrick, D. M. Follett, and C. J. Czuprynski, Cytokine regulation of the intracellular growth of Mycobacterium paratuberculosis in bovine monocytes, Infect Immunol 56 (1988), pp. 1692-1697. 